
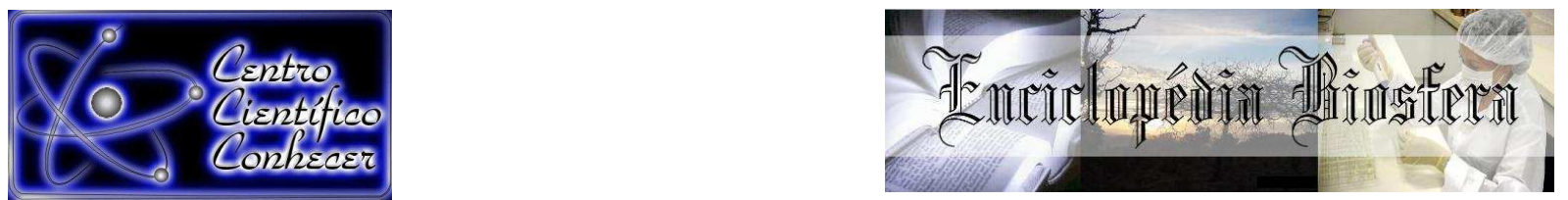

\title{
COMPORTAMENTO DA PRECIPITAÇÃO PLUVIOMÉTRICA EM TRÊS MUNICÍPIOS DO ESTADO DO PARANÁ, COMO SUBSÍDIO PARA PREVENÇÃO DE INCÊNDIOS FLORESTAIS
}

\author{
Igor Kiyoshi Takashina1; Bruna Kovalsyki; Tatiane Lima Ho2; Alexandre França Tetto², \\ Antonio Carlos Batista ${ }^{3}$ \\ ${ }^{1}$ Mestrando no programa de pós-graduação em Engenharia Florestal da Universidade \\ Federal do Paraná - UFPR (igor.takashina@gmail.com) Curitiba - Brasil. \\ ${ }^{2}$ Pesquisadora DTI-CNPQ. \\ ${ }^{3}$ Professor Doutor do Departamento de Ciências Florestais - UFPR.
}

Recebido em: 08/09/2015 - Aprovado em: 14/11/2015 - Publicado em: 01/12/2015 DOI: http://dx.doi.org/10.18677/Enciclopedia_Biosfera_2015_115

\begin{abstract}
RESUMO
Incêndio florestal é o fogo sem controle que incide sobre uma vegetação, sendo que a probabilidade e frequência de sua ocorrência estão relacionadas às variáveis meteorológicas. Neste contexto, o presente trabalho teve como objetivo analisar e comparar os dados de precipitação de três municípios da região centro-sul do estado do Paraná, como subsídio ao planejamento das atividades de prevenção e combate aos incêndios. Os dados de precipitação foram obtidos das estações meteorológicas do Instituto Agronômico do Paraná, referentes ao período de 1980 a 2009, dos municípios de Guarapuava, Laranjeiras do Sul e Quedas do Iguaçu, Paraná. Foram analisados os valores médios da precipitação mensal $(\mathrm{mm})$, valores da precipitação anual $(\mathrm{mm})$ e média do número de dias de chuva por mês. Os resultados indicaram que os meses que apresentaram menor precipitação, e consequentemente são mais vulneráveis à ocorrência dos incêndios, foram março, julho e agosto, sendo que este último se destacou dos demais, por representar apenas $5 \%$ da precipitação anual e apresentar a menor quantidade de dias de chuva, sendo a precipitação média anual dos três municípios de aproximadamente 2032,6 mm. Os municípios estudados demonstraram comportamento semelhante quanto à precipitação pluviométrica ao longo do período analisado, não havendo diferença estatística entre eles. Deste modo, conclui-se que as atividades de prevenção aos incêndios florestais devem ser intensificadas nestes meses, como forma de minimizar os impactos causados por esses eventos.
\end{abstract}

PALAVRAS-CHAVE: Climatologia, Incêndios Florestais, Meteorologia, Proteção Florestal

\section{RAINFALL BEHAVIOR IN THREE CITIES OF THE STATE OF PARANÁ, AS A SUBISIDY TO PREVENT FOREST FIRES}

\begin{abstract}
Forest fire is uncontrolled fire that focuses on vegetation, and the likelihood and frequency of their occurrence are related to weather variables. In this context, this study
\end{abstract}


aimed to analyze and compare the three cities rainfall data center-south region of the state of Parana, as input to the planning of activities to prevent and combat wild fires. The rainfall data were obtained from the meteorological stations of the Agronomic Institute of Paraná, for the period 1980-2009, of Guarapuava, Laranjeiras do Sul and Quedas do Iguaçu cities. The average values of monthly precipitation were analyzed values of annual precipitation $(\mathrm{mm})$ and average number of rainy days per month $(\mathrm{mm})$. The results showed that the months had lower rainfall, and therefore are more vulnerable to the occurrence of fires, were March, July and August, the latter stood out from the others, it represents only $5 \%$ of the annual precipitation and present the least amount rainy days, the average annual precipitation in the three municipalities of approximately $2032.6 \mathrm{~mm}$. The cities studied showed similar behavior in terms of rainfall over the analysis period, with no statistical difference between them. Thus, it is concluded that the activities of prevention of forest fires should be intensified in recent months, in order to minimize the impacts caused by such events.

KEYWORDS: Climatology, Forest Fire, Meteorology, Forest Protection

\section{INTRODUÇÃO}

Os maiores e mais destrutivos incêndios florestais registrados no mundo, ocorreram sob combinações ideais de material combustível e condições climáticas e, apesar da adoção de práticas protecionistas, a cada ano o fogo destrói ou danifica grandes extensões florestais no mundo (SOARES \& BATISTA, 2007), sendo considerado um dos principais agentes causadores de danos às florestas (TETTO et al., 2011). Os principais fatores que influenciam o comportamento do fogo, sobretudo a ignição e a propagação dos incêndios são: temperatura, umidade relativa do ar, precipitação e vento (BATISTA et al., 2002). O conhecimento destes dados meteorológicos auxilia no planejamento de prevenção e combate a incêndios florestais (NUNES et al., 2005).

MÉRIDA (2000) relata que além da influência sobre o teor de umidade dos materiais combustíveis, a umidade do ar influencia também na disponibilidade de oxigênio para o processo de combustão. Uma maior umidade relativa do ar implica em uma menor proporção de oxigênio no ambiente, o que significa um retardo no processo. Deste modo, de acordo com SOARES (1985), a umidade relativa é um dos fatores fundamentais na propagação dos incêndios florestais e um elemento importante na avaliação do grau de dificuldade de combate aos incêndios.

A precipitação influi diretamente na umidade relativa do ar e dos combustíveis mortos e, dias depois, dos combustíveis vivos, por meio da incorporação da água do solo nos tecidos das plantas (MÉRIDA, 2000), tornando-se assim o fator fundamental para reduzir o potencial de ocorrência e propagação dos incêndios. A quantidade de água precipitada e sua distribuição estacional definem o início, o término e a duração da estação normal de perigo de incêndio (SOARES, 1985; BATISTA, 1990).

Segundo DEPPE et al. (2004), as estações outono, inverno e primavera, mais especificamente os meses de maio a outubro, apresentam uma alta ocorrência de incêndios no estado do Paraná. Neste mesmo período se observam baixos índices pluviométricos e, segundo os mesmos autores, em locais com déficit de chuva, a baixa 
umidade e a presença de geadas, faz com que haja um aumento da combustibilidade da vegetação e, consequentemente, aumento do risco de ocorrência de incêndios.

Neste contexto, o presente trabalho teve por objetivo analisar e comparar o comportamento da precipitação nos municípios de Guarapuava, Laranjeiras do Sul e Quedas do Iguaçu para o período de 1980 a 2009, visando o planejamento das atividades que evitem a ocorrência e propagação dos incêndios florestais na região.

\section{Área de estudo}

\section{MATERIAL E MÉTODOS}

Os municípios analisados localizam-se na região centro-sul do estado do Paraná, sendo estes: Guarapuava, Laranjeiras do Sul e Quedas do Iguaçu. Estes compõem a Microrregião Geográfica de Guarapuava (MRG - 29) juntamente com outros 15 municípios (INSTITUTO PARANAENSE DE DESENVOLVIMENTO ECONÔMICO E SOCIAL - IPARDES, 2010) (Figura 1).

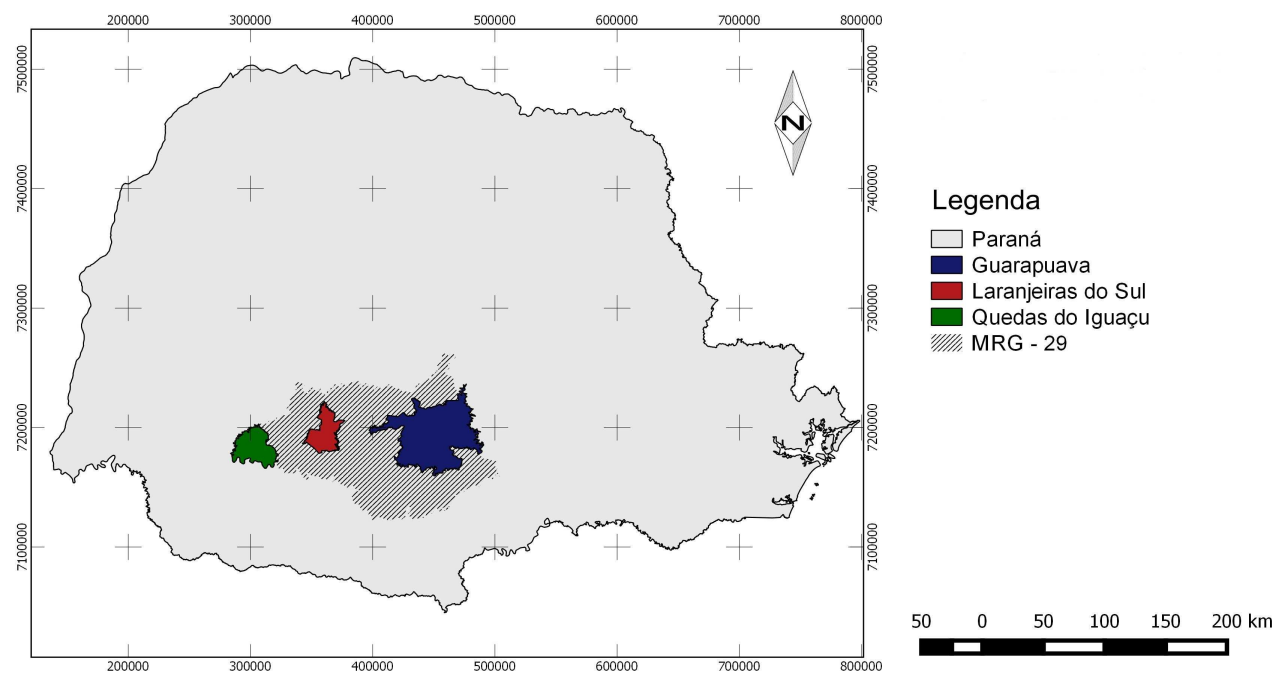

FIGURA 1 Localização da área de estudo.

Fonte: OS AUTORES (2015).

De acordo com o Instituto Brasileiro de Geografia e Estatística - IBGE (2015),

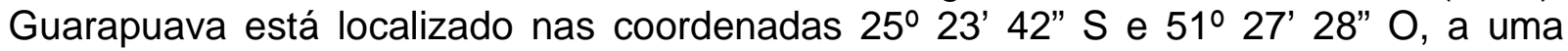
altitude de $1098 \mathrm{~m}$ e abrange uma área de $3.117,01 \mathrm{~km}^{2}$. Conforme a classificação de Köppen, apresentada pelo Instituto Agronômico do Paraná - IAPAR (2015), o clima do município é classificado como $\mathrm{Cfb}$, clima temperado propriamente dito, cuja temperatura média do mês mais frio é inferior a $18^{\circ} \mathrm{C}$ (mesotérm ico), enquanto a temperatura média no mês mais quente é inferior a $22^{\circ} \mathrm{C}$, com verões frescos e sem estação seca definida. Segundo o Instituto, para o período de 1976 a 2004, Guarapuava apresentou uma temperatura média do mês mais frio de $13,9^{\circ} \mathrm{C}$, correspondente ao mês de julho, e para o mês mais quente a temperatura média registrada foi de $21,7{ }^{\circ} \mathrm{C}$ no mês de janeiro.

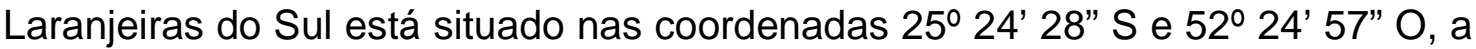
uma altitude de $840 \mathrm{~m}$ e apresenta uma área de $672,08 \mathrm{~km}^{2}$, enquanto Quedas do 
Iguaçu localiza-se nas coordenadas 25 $27^{\prime} 00^{\prime \prime} S$ e 52 $54^{\prime} 28^{\prime \prime} \mathrm{O}$, a uma altitude de 562 $\mathrm{m}$ e abrange uma área de $821,50 \mathrm{~km}^{2}$ (IBGE, 2015). Segundo o IAPAR (2015), o clima nestas cidades é classificado como $\mathrm{Cfa}$, clima subtropical, com temperatura média do mês mais frio inferior a $18^{\circ} \mathrm{C}$ (mesotérmico) e temp eratura média no mês mais quente superior a $22^{\circ} \mathrm{C}$ apresenta verões quentes, geadas p ouco frequentes e tendência de concentração das chuvas nos meses de verão, contudo sem estação seca definida. Conforme o IAPAR, os dados meteorológicos registrados para o município de Laranjeiras do Sul no período de 1974 a 2004, julho foi o mês que apresentou a temperatura média mais fria com $16,3^{\circ} \mathrm{C}$, e o mês ma is quente, com temperatura média de $23,1^{\circ} \mathrm{C}$, foi janeiro. Enquanto para Quedas do Iguaçu, para o período registrado de 1974 a 1998, a temperatura média do mês mais frio foi de $16,3^{\circ} \mathrm{C}$, referente a junho, e a temperatura média do mês mais quente foi de $25,2{ }^{\circ} \mathrm{C}$, em janeiro.

\section{Processo Metodológico}

Para realização do trabalho foram utilizados dados de precipitação diária das estações meteorológicas dos municípios de Guarapuava, Laranjeiras do Sul e Quedas do Iguaçu, do Instituto Agronômico do Paraná (IAPAR), para o período de 1980 a 2009.

Os dados foram processados no programa Excel, obtendo-se a média do número de dias de chuva por mês e o coeficiente de variação, para os quais foram considerados os dias com valor da precipitação pluviométrica diferente de zero, assim como os valores médios da precipitação mensal $(\mathrm{mm})$ e precipitação anual $(\mathrm{mm})$. Estes dois últimos fatores foram submetidos a análise estatística ANOVA, ao nível de significância de 5\%, com auxílio do software Statistica 7.0.

\section{RESULTADOS E DISCUSSÃO}

As Figuras 2 e 3 apresentam a comparação estatística da precipitação anual e mensal, respectivamente, nas quais não foram evidenciadas diferença estatística significativa entre os municípios.

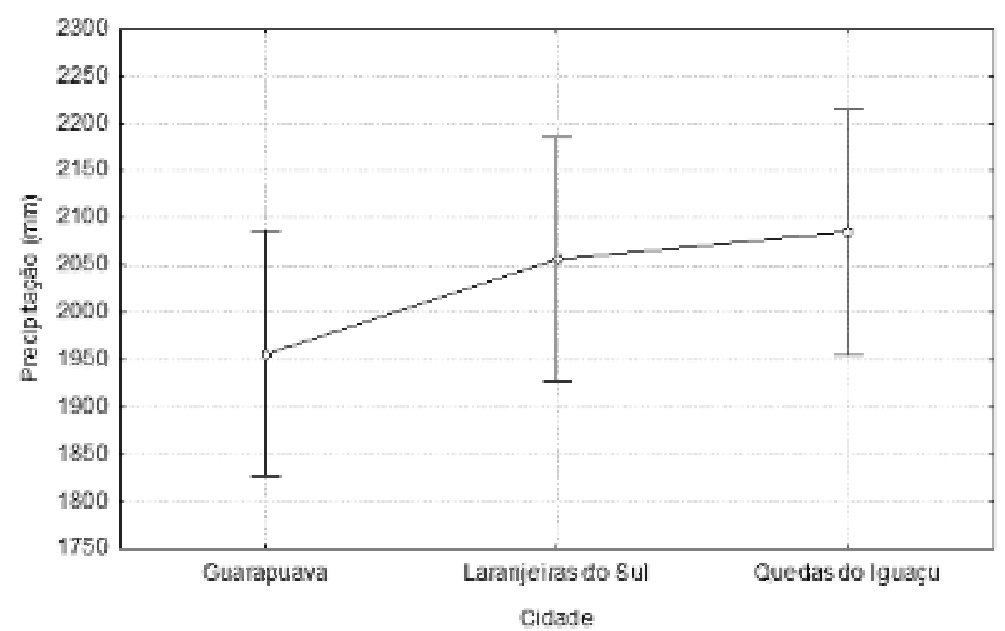

FIGURA 2 Comparação da precipitação anual no período de 1980 a 2009 dos municípios de Guarapuava, Laranjeiras do Sul e Quedas do Iguaçu. 


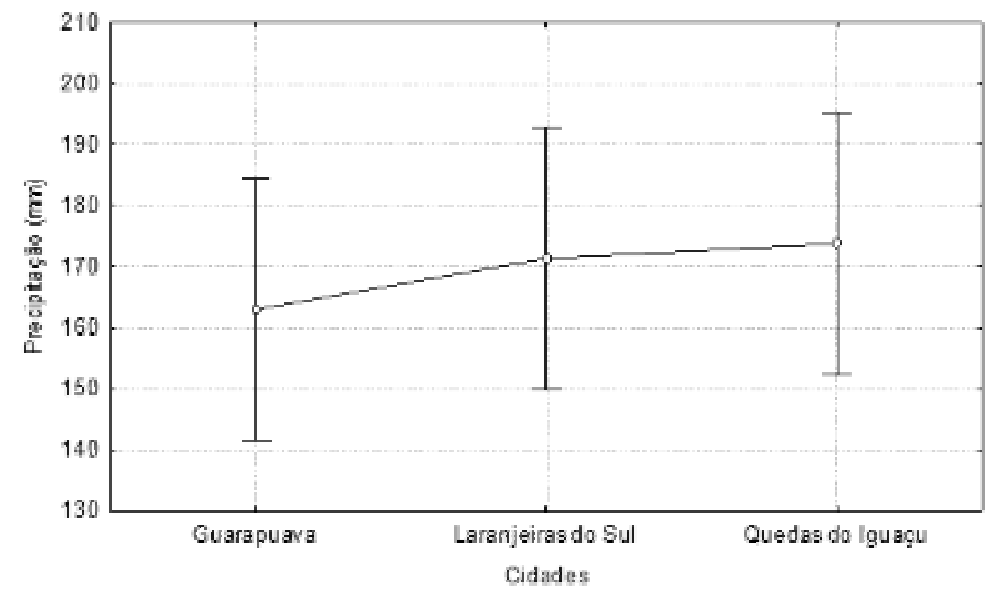

FIGURA 3: Comparação da precipitação mensal no período de 1980 a 2009 nos municípios de Guarapuava, Laranjeiras do Sul e Quedas do Iguaçu.

A Figura 4 a seguir apresenta a média mensal de dias de chuva e a precipitação média mensal, referente ao período analisado, para os municípios de Guarapuava, Laranjeiras do Sul e Quedas do Iguaçu.
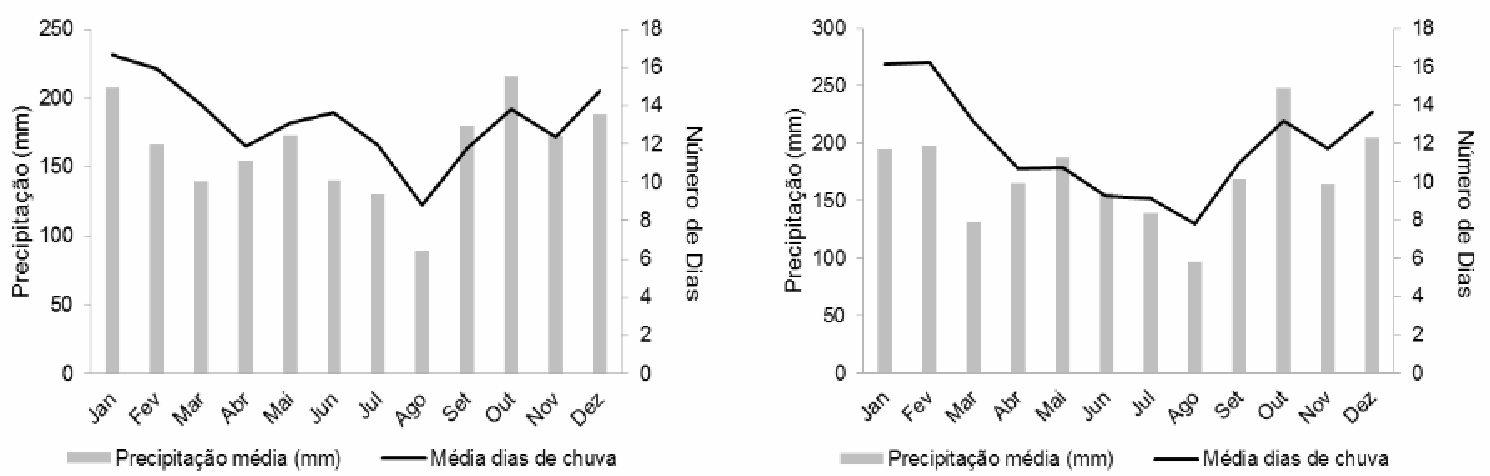

A

B

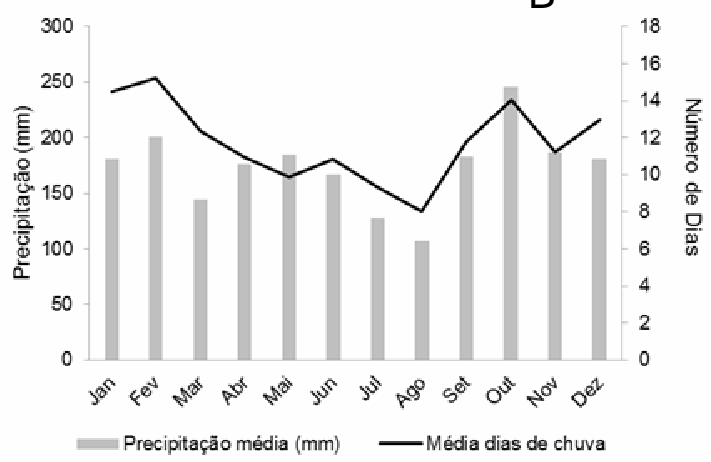

C

FIGURA 4 Valores médios da precipitação mensal e média do número de dias de chuva dos municípios: (A) Guarapuava; (B) Laranjeiras do Sul; e (C) Quedas do Iguaçu, no período de 1980 a 2009 
Para os três municípios observou-se que o mês de agosto apresentou menor precipitação (aproximadamente $5 \%$ da precipitação anual), assim como menor número de dias de chuva, seguido dos meses de março e julho, enquanto o mês mais chuvoso foi outubro, com $11,6 \%$ da precipitação anual (Tabela 1). A estação que apresentou menor precipitação pluviométrica foi o inverno (junho, julho e agosto), cerca de $19 \%$ da precipitação anual, com um número médio de dias de chuva de 27 a 2 . Por outro lado, os meses de primavera (setembro, outubro e novembro) corresponderam a aproximadamente $28,9 \%$ da precipitação anual, apresentando uma frequência média de dias de chuva de 23 a 4 dias (Tabela 2).

TABELA 1 Valores médios $(\mathrm{mm})$, mínimos $(\mathrm{mm})$, máximos $(\mathrm{mm})$ e coeficiente de variação (\%) das precipitações mensais de 1980 a 2009.

\begin{tabular}{|c|c|c|c|c|c|c|c|c|c|c|c|c|}
\hline \multirow{2}{*}{ Mês } & \multicolumn{4}{|c|}{ Guarapuava } & \multicolumn{4}{|c|}{ Laranjeiras do Sul } & \multicolumn{4}{|c|}{ Quedas do Iguaçu } \\
\hline & Med & Mín & Máx & CV & Med & Mín & Máx & CV & Med & Mín & Máx & CV \\
\hline Janeiro & 207,7 & 36,5 & 404,4 & 42,2 & 194,9 & 37,0 & 480,6 & 45,5 & 180,7 & 22,2 & 438,4 & 54,9 \\
\hline Fevereiro & 166,1 & 67,3 & 331,8 & 41,8 & 197,7 & 22,9 & 433,6 & 49,3 & 201,1 & 52,1 & 431,6 & 48,1 \\
\hline Março & 139,4 & 53,4 & 282,3 & 40,7 & 131,8 & 51,1 & 285,3 & 47,0 & 144,3 & 35,2 & 360,2 & 52,6 \\
\hline Abril & 154,4 & 27,8 & 518,0 & 60,6 & 165,2 & 40,8 & 501,7 & 55,4 & 176,7 & 31,1 & 564,0 & 61,4 \\
\hline Maio & 172,8 & 18,6 & 512,8 & 78,8 & 187,0 & 8,9 & 502,9 & 72,4 & 185,0 & 23,8 & 557,5 & 72,0 \\
\hline Junho & 140,7 & 12,9 & 400,0 & 63,6 & 157,0 & 14,4 & 383,1 & 59,9 & 166,8 & 29,4 & 310,9 & 51,2 \\
\hline Julho & 130,2 & 9,4 & 471,8 & 72,9 & 139,4 & 7,9 & 452,1 & 68,6 & 127,8 & 13,9 & 533,2 & 78,9 \\
\hline Agosto & 89,0 & 3,2 & 287,4 & 77,8 & 97,0 & 6,8 & 243,8 & 76,3 & 106,8 & 7,1 & 282,2 & 75,2 \\
\hline Setembro & 179,8 & 28,0 & 396,5 & 55,9 & 168,6 & 19,3 & 365,1 & 61,2 & 182,5 & 20,2 & 349,2 & 50,8 \\
\hline Outubro & 215,6 & 69,2 & 376,7 & 38,9 & 248,5 & 59,0 & 476,2 & 39,3 & 246,0 & 61,2 & 512,9 & 40,5 \\
\hline Novembro & 172,5 & 25,1 & 492,8 & 54,5 & 164,3 & 31,2 & 533,8 & 57,6 & 186,4 & 44,8 & 642,1 & 62,8 \\
\hline Dezembro & 187,8 & 45,7 & 300,0 & 39,1 & 205,0 & 54,0 & 465,8 & 48,4 & 181,4 & 46,4 & 402,8 & 48,6 \\
\hline
\end{tabular}

TABELA 2: Valores médios, mínimos, máximos e coeficiente de variação do número de dias de chuva mensais de 1980 a 2009.

\begin{tabular}{l|rrrrrrrr|rrrr}
\hline \multicolumn{1}{c}{ Mês } & \multicolumn{4}{c}{ Guarapuava } & \multicolumn{4}{c|}{ Laranjeiras do Sul } & \multicolumn{3}{c}{ Quedas do Iguaçu } \\
& Med & Mín & Máx & CV & Med & Mín & Máx & CV & Med & Mín & Máx & CV \\
\hline Janeiro & 17 & 7 & 25 & 30 & 16 & 6 & 28 & 31 & 15 & 3 & 23 & 34 \\
Fevereiro & 16 & 6 & 24 & 27 & 16 & 7 & 25 & 28 & 15 & 4 & 23 & 29 \\
Março & 14 & 8 & 24 & 32 & 13 & 7 & 19 & 28 & 12 & 5 & 19 & 29 \\
Abril & 12 & 4 & 21 & 37 & 11 & 5 & 16 & 28 & 11 & 5 & 17 & 34 \\
Maio & 13 & 3 & 29 & 52 & 11 & 4 & 20 & 43 & 10 & 5 & 18 & \\
Junho & 14 & 5 & 25 & 41 & 9 & 4 & 19 & 38 & 11 & 4 & 18 & 36 \\
Julho & 12 & 5 & 27 & 47 & 9 & 4 & 18 & 40 & 9 & 3 & 22 & 47 \\
Agosto & 9 & 2 & 18 & 51 & 8 & 2 & 16 & 50 & 8 & 2 & 18 & 45 \\
Setembro & 12 & 5 & 21 & 33 & 11 & 5 & 18 & 36 & 12 & 5 & 21 & 32 \\
Outubro & 14 & 7 & 22 & 29 & 13 & 6 & 20 & 28 & 14 & 8 & 22 & 25 \\
Novembro & 12 & 6 & 22 & 30 & 12 & 5 & 20 & 32 & 11 & 4 & 23 & 38 \\
Dezembro & 15 & 8 & 23 & 24 & 14 & 7 & 20 & 24 & 13 & 7 & 20 & 24 \\
\hline Nota: Med: Médian
\end{tabular}

Nota: Med: Média, Mín: Mínimo, Máx: Máximo e CV: Coeficiente de variação (\%) 
NUNES et al. (2009), em um estudo sobre a precipitação no distrito florestal de Monte Alegre em Telêmaco Borba - PR, verificaram que os meses de menor incidência de chuvas foram abril, julho e agosto, enquanto TETTO et al. (2010), para o município de Fernandes Pinheiro, constataram os meses de março, julho e agosto.

SOUSA (2006) observou que no estado do Paraná, considerando o período de 1972 a 2002, os meses mais chuvosos foram dezembro e janeiro, enquanto junho, julho e agosto foram os meses mais secos. O autor relata que no verão há um predomínio de massa de ar quente e úmida que provoca aumento na distribuição de chuvas neste período, sendo janeiro o mês com maior frequência de dias com chuva (de 9 a 17 dias), por outro lado, na estação de inverno há um predomínio da massa polar e ocorre um declínio acentuado na distribuição da precipitação, na qual a maior frequência de precipitação alcança no máximo 24 e o mínimo de 12 dias.

Conforme SOARES \& SANTOS (2002), a estação de ocorrência de incêndios no Brasil estende-se desde julho até novembro. Já para o estado Paraná, VOSGERAU et al. (2006) relatam que os meses de maior ocorrência de incêndios foram julho, agosto e setembro, enquanto TETTO et al. (2012) observaram que 52,5\% dos registros de incêndios no estado, para o período de 2005 a 2010, ocorreram nos meses de julho a setembro. Desta forma, os autores descrevem que o problema dos incêndios florestais no país concentra-se no inverno e início da primavera, período que corresponde à estação mais seca do ano em quase todo o território nacional. Os últimos autores observaram que as ocorrências de incêndios florestais no Paraná estão diretamente relacionadas à quantidade e distribuição da precipitação pluviométrica.

A Figura 5 apresenta o comportamento da precipitação pluviométrica anual ao longo do período analisado. Guarapuava e Laranjeiras do Sul apresentaram uma tendência de diminuição da precipitação total anual, já em Quedas do Iguaçu, houve uma tendência de aumento, mesmo comportamento encontrado por NUNES et al. (2009) ao analisarem a região de Telêmaco Borba. Pela integração dos gráficos observou-se que, até o ano de 2005, a oscilação da precipitação teve um comportamento semelhante entre os municípios. 


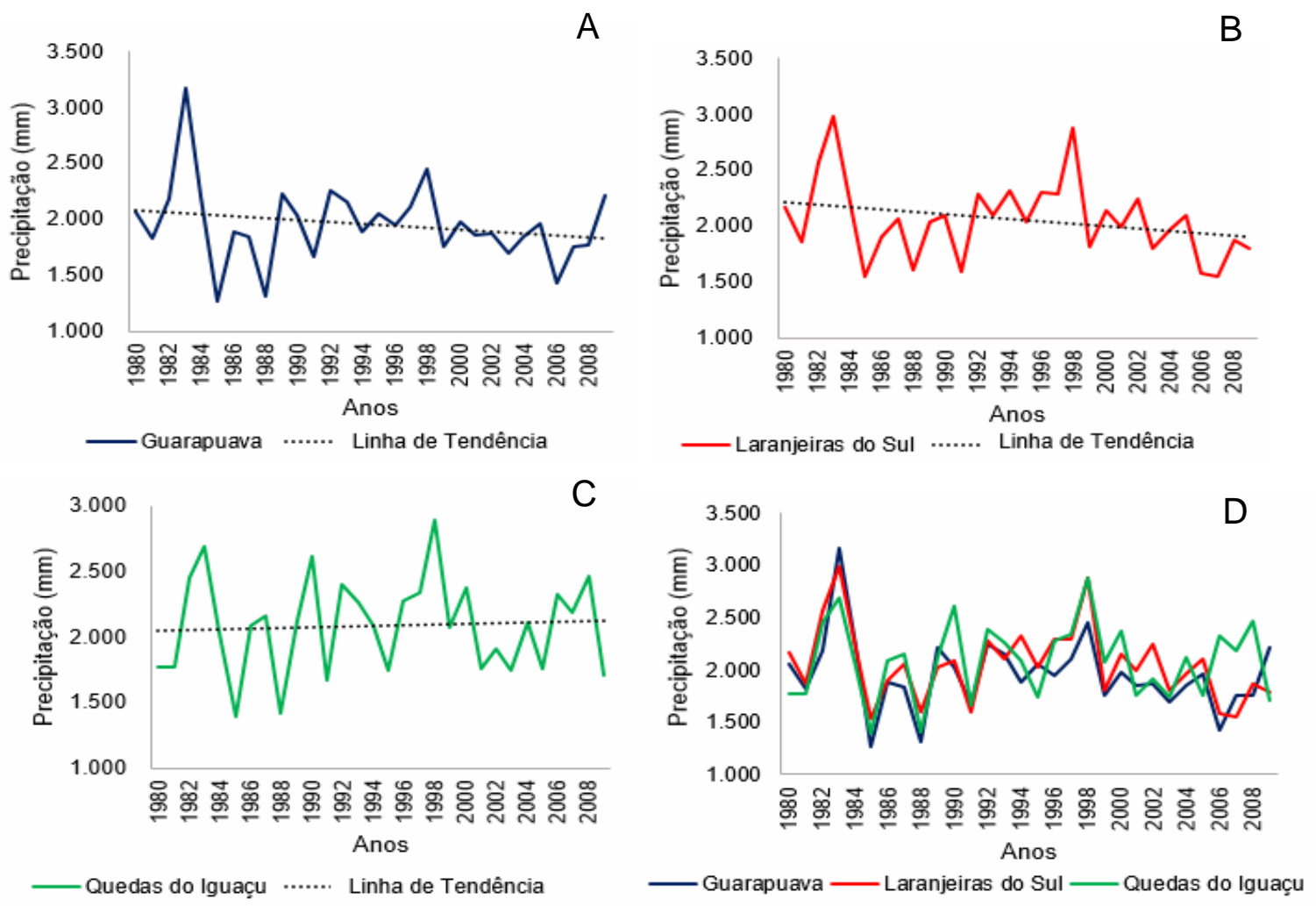

FIGURA 5: Precipitação anual no período de 1980 a 2009. (A) Guarapuava; (B) Laranjeiras do Sul; (C) Quedas do Iguaçu; e (D) Integração dos três municípios.

A variação da precipitação pluviométrica no período de 1980 a 2009 para o município de Guarapuava variou de 1262,1 a 3168,4 mm, com média de 1955,99 mm. Segundo TETTO et al. (2012), de 2005 a 2010 a precipitação apresentou uma variação de 1426,8 a $2196,3 \mathrm{~mm}$, e média de $1797,1 \mathrm{~mm}$ para o mesmo município. Para Laranjeiras do Sul a variação foi de 1542,90 a 2986,1 mm com média de 2056,24 mm. Em Quedas do Iguaçu a precipitação variou de 1396,90 a $2885,70 \mathrm{~mm}$ e média de $2085,52 \mathrm{~mm}$ no período. Considerando os três municípios no período em análise, o total médio da precipitação foi de 2.032,6 mm, valor superior se comparado com município de Irati com um total médio de 1599,3 mm no período de 1963 a 2005 (TETTO et al., 2010) e o município de Telêmaco Borba com um total médio de 1.523,3 mm no período de 1947 a 2005 (NUNES et al., 2009).

Conforme SOUSA (2006), a variabilidade da precipitação pluvial no Paraná está fortemente associada aos eventos El Niño, no qual observa-se elevação na quantidade de precipitação (anomalia positiva), como também redução na quantidade de precipitação (anomalia negativa) durante eventos de La Niña, os quais podem ser evidenciados na Figura 3. O autor descreve que na década de 1980 ocorreram três eventos importantes no estado, correspondentes aos anos de 1983, 1985 e 1988. Em 1983 houve influência do El Niño, o qual causou uma anomalia positiva, afetando principalmente a região centro-sul do estado com valores entre 800 a $1200 \mathrm{~mm}$ acima da normal climatológica (1600 a 2000 mm). Para 1985 e 1988 observou-se uma 
anomalia negativa, redução em torno de $600 \mathrm{~mm}$ da precipitação pluvial, decorrente do evento La Niña. Quanto à década de 1990, o mesmo autor relata que ocorreu uma série de eventos, destacando-se o ano de 1998, no qual houve uma anomalia positiva, apresentando um acréscimo dentre 400 a $800 \mathrm{~mm}$.

\section{CONCLUSÕES}

O estudo permitiu analisar e comparar o comportamento da precipitação nos municípios de Guarapuava, Laranjeiras do Sul e Quedas do Iguaçu. Os meses com os menores registros de precipitação foram constatados no período de março, julho e agosto, indicando uma maior probabilidade de ocorrência de incêndios e concentração das atividades de prevenção e combate aos incêndios florestais. O comportamento da precipitação ao longo dos 30 anos apresentou algumas anomalias (positivas e negativas) que podem ser explicadas pelos eventos El Niño e La Niña.

\section{AGRADECIMENTOS}

Ao Instituto Agronômico do Paraná, pelo fornecimento dos dados meteorológicos.

\section{REFERÊNCIAS}

BATISTA, A. C. Incêndios florestais. Recife: Imprensa Universitária da UFRPE, 1990. $115 \mathrm{p}$.

BATISTA, A. C.; OLIVEIRA, D. S.; SOARES, R. V. Zoneamento de risco de incêndios florestais para o estado do Paraná. Curitiba: Fupef; 2002. 82 p. (Série Técnica, n02/02). Disponível em: <http://dx.doi.org/10.5380/rf.v34i2.2399>.

DEPPE, F.; PAULA, E. V.; MENEGHETTE, C. R.; VOSGERAU, J. Comparação de índices de risco de incêndio florestal com focos de calor no estado do Paraná. FLORESTA, Curitiba, v. 34, n. 2, p. 119 - 126, 2004. Disponível em: <http://dx.doi.org/10.5380/rf.v34i2.2382>.

INSTITUTO AGRONÔMICO DO PARANÁ - IAPAR. Cartas climáticas do Paraná. 2015. Disponível em:<http://www.iapar.br/modules/conteudo/conteudo.php?conteudo=8 63>. Acesso em: 25 jun. 2015.

INSTITUTO BRASILEIRO DE GEOGRAFIA E ESTATÍSTICA - IBGE. Cidades@. 2015. Disponível em: http://www.cidades.ibge.gov.br/xtras/uf.php?lang=\&coduf=41\&search=p arana>. Acesso em: 25 jun.2015.

INSTITUTO PARANAENSE DE DESENVOLVIMENTO ECONÔMICO E SOCIAL IPARDES. Estado do Paraná: Microrregiões Geográficas. 2010. Disponível em: < http://www.ipardes.gov.br/pdf/mapas/base_fisica/microrregioes_geograficas_base_2010 .pdf>. Acesso em: 25 jun. 2015.

MÉRIDA, J. C. F. Factores ambientales. In: VÉLEZ, R. M. (Coord.). La defensa contra incendios forestales: fundamentos y experiencias. Madrid: McGRAW-HILL, 2000. p. $8.1-8.11$. 
NUNES, J. R. S.; SOARES, R. V.; BATISTA, A. C. Estimativa da umidade relativa das 13:00 h, com base nos dados das 9:00 h e das 15:00 h, para o estado do Paraná. FLORESTA, v. 35, n. 2, 2005. Disponível em: <http://dx.doi.org/10.5380/rf.v35i2.4612>

NUNES, J.R.S.; BATISTA, A.C., SOARES; R.V., NAMIKAWA, I.S.; SANTOS, C.C. Climatologia do comportamento da precipitação no Distrito Florestal de Monte Alegre, PR, Brasil. FLORESTA, Curitiba, v. 39, n.4, p. 783-792, 2009. Disponível em: $<$ http://dx.doi.org/10.5380/rf.v39i4.16313>.

SOARES, R.V.; SANTOS, J.F. Perfil dos incêndios florestais no Brasil de 1994 a 1997. FLORESTA, v.32, n.2, p. 219-232, 2002. Disponível em: $<$ http://dx.doi.org/10.5380/rf.v32i2.2287>.

SOARES, R. V. Incêndios florestais: controle e uso do fogo. Curitiba: FUPEF, 1985. $213 \mathrm{p}$.

SOARES, R. V.; BATISTA, A. C. Incêndios Florestais: controle, efeitos e uso do fogo. $1^{\text {rd }}$ ed. Curitiba. 2007. 264 p.

SOUSA, P. Estudo da variabilidade da precipitação no estado do Paraná associado à anomalia da TSM no oceano Pacífico. $84 \mathrm{f}$. Dissertação (Mestrado em Geografia) - Departamento de Geografia, Universidade Estadual de Maringá, Maringá, 2006.

TETTO, A.F.; BATISTA, A. C.; NUNES, J. R. S.; SOARES R. V. Subsídio à prevenção e combate a incêndios florestais com base no comportamento da precipitação pluviométrica na Floresta Nacional de Irati, Paraná. Ciência Florestal, v. 20, n.1, p. 3343, 2010. Disponível em: < http://dx.doi.org/10.5902/19805098>.

TETTO, A. F.; BATISTA, A. C; SOARES, R. V. Prevenção e combate aos incêndios florestais. Curitiba: SENAR-PR. 2011.

TETTO, A.F.; BATISTA, A. C.; SOARES R. V. Ocorrência de incêndios florestais no estado do Paraná, no período de 2005 a 2010. FLORESTA, v. 42, n.2, p. 391-398, 2012. Disponível em: <http://dx.doi.org/10.5380/rf.v42i2.22516>.

VOSGERAU, J. L.; BATISTA, A.C., SOARES; R.V., GRODZKI, L. Avaliação dos registros de incêndios florestais do estado do Paraná no período de 1991 a 2001. FLORESTA, Curitiba, v. 36, n.1, p. 23-32, 2006. Disponível em: $<$ http://dx.doi.org/10.5380/rf.v36i1.5608>. 